\title{
Aplicação do Método Eletromagnético Transiente em área sob Atenuação Natural
} César Augusto Moreira, João Carlos Dourado-UNESP / Brasil

Copyright 2004, SBGf - Sociedade Brasileira de Geofísica

Este texto foi preparado para a apresentação no I Simpósio de Geofísica da Sociedade Brasileira de Geofísica, São Paulo, 26-28 de setembro de 2004. Seu conteúdo foi revisado pela Comissão Tecno-científica do I SR-SBGf mas não necessariamente representa a opinião da SBGf ou de seus associados. E proibida a reprodução total ou parcial deste material para propósitos comerciais sem prévia autorização da SBGf.

\section{Resumo}

As técnicas geofísicas podem ser utilizadas em conjunto com técnicas diretas de análise do meio, como análises químicas em água e solo e na determinação da eficiência do processo de remediação de áreas contaminadas. A aplicação do método Eletromagnético Transiente em uma área contaminada por derivados de petróleo, atualmente sob processo de atenuação natural, permitiu a delimitação da pluma de contaminação, caracterizada por uma anomalia de baixa resistividade. A baixa resistividade da pluma de contaminação pode estar associada ä presença de elevados teores de sódio e cloreto, em conjunto com íons liberados a partir da dissolução mineral por ação de ácidos gerados durante o processo de biodegradação dos compostos orgânicos.

Introdução

O intenso do processo de industrialização iniciado a partir da segunda metade do século $X X$ propiciou 0 crescimento e o progresso do Estado de São Paulo. Este desenvolvimento resultou na geração de empregos e renda, elevando o padrão e a qualidade de vida de seus habitantes.

O resultado negativo deste processo é a extenso passivo ambiental herdado de décadas de falta de planejamento e descaso com o meio ambiente, com a degradação de rios, solo e água subterrânea. $O$ órgão ambiental estadual havia registrado até maio de 2002 um total de 255 áreas contaminadas (CETESB, 2003).

O diagnóstico de áreas potencialmente contaminadas assim como o monitoramento destas áreas são necessários devido ao risco a saúde e a qualidade de vida da população.

Os métodos geofísicos são uma alternativa aos problemas levantados, devido a rapidez e o baixo custo em estudos de diagnóstico ambiental.

O método Eletromagnético Transiente (TEM) é um dos diversos métodos geofísicos que podem ser utilizados no estudo de contaminações em solo e água subterrânea.

Este trabalho apresenta os resultados da aplicação desta técnica em uma área contaminada por derivados de petróleo, sob processo de atenuação natural.

\section{Materiais e Métodos}

O método eletromagnético transiente (TEM) envolve uma bobina transmissora pela qual circula uma corrente periódica que induz um campo magnético, que induz uma voltagem periódica e que, por sua vez, produz um campo magnético secundário, captado por uma bobina receptora (figura 1).

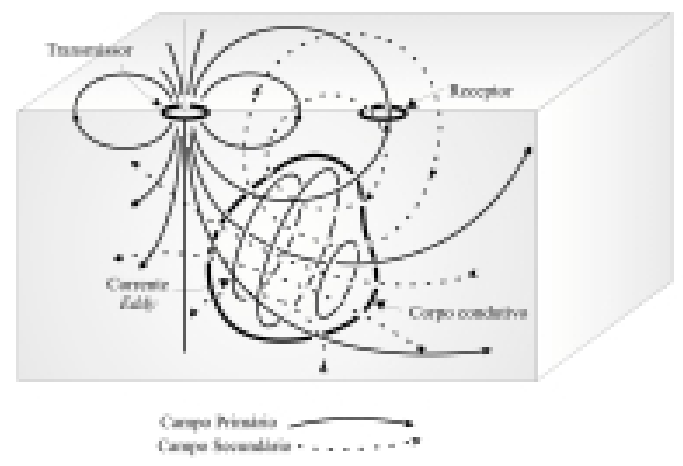

Figura 1 - Princípio do Método Eletromagnético Transiente (Sheriff, 1989)

A corrente eddy é obtida a partir da intensidade do campo magnético secundário $(H s)$ medida pela bobina receptora. Na prática, são comparados os valores de $H s$ com a intensidade do campo magnético primário $(H p)$. Como a posição da bobina transmissora e o valor de corrente transmitido são conhecidos, o valor de $H p$ pode ser calculado.

O resultado da sondagem TEM é uma seção geoelétrica obtida pela medida da componente vertical da corrente eddy em função do tempo.

O equipamento TEM utilizado foi o sistema PROTEM, modelo 47D, fabricado pela Geonics Limited (Canadá).

Foi adotado o arranjo de $5 \times 5$ metros para a bobina transmissora e disposição central da bobina receptora 1D. Os dados foram adquiridos a partir de leituras pontuais com espaçamento de 15 metros entre pontos, cuja integração permitiu a apresentação dos resultados sob a forma de mapas e seções.

Após testes preliminares na área para calibração do equipamento, foram definidos os seguintes parâmetros:

\begin{tabular}{|l|l|}
\hline Parâmetro & Ajuste \\
\hline Sistema de canais & 20 \\
\hline Taxa de Repetição & $30 \mathrm{~Hz}$ \\
\hline Ganho & 1 \\
\hline Tempo de Integração & 15 segundos \\
\hline Tempo de desligamento & $2 \mu \mathrm{s}$ \\
\hline
\end{tabular}


Os dados foram inicialmente extraídos do equipamento a partir do programa PROTEM D, e posteriormente processados por meio do programa TEM Temix XL v4, produzido pela Interpex limitada.

A corrente aplicada na bobina transmissora variou entre 1 a 2,5 A, com valores mais elevados para pontos mais ruidosos, com o objetivo de atingir a melhor relação sinal/ruído. Desta forma, a freqüência do campo eletromagnético também foi variável:

\begin{tabular}{|l|l|}
\hline Corrente $(\mathrm{A})$ & Freqüência $(\mathrm{Hz})$ \\
\hline 1 & 351 \\
\hline 1,5 & 75 \\
\hline 2,5 & 75 \\
\hline
\end{tabular}

Neste trabalho são apresentadas duas linhas de aquisição de dados, denominadas LA e LC.

A linha LA é constituída por seis sondagens, com início em na sondagem LA1, com latitude 252207 e longitude 7523259. Segue o azimute N5 até a sondagem LA6, de latitude 252225 e longitude 7523331.

A linha LC é constituída por sete sondagens, com início na sondagem LC1, de latitude 252275 e longitude 7523341. Segue o azimute N10 até a sondagem LC7, de latitude 252239 e longitude 7523241.

\section{Localização e Histórico da Área}

A área de estudos está localizada no município de Araras, estado de São Paulo, precisamente no Km 51,2 da rodovia SP 191, que liga as cidades de Araras e Rio Claro (Figura 2). O acesso a partir da rodovia SP 330 é feito no cruzamento com a rodovia SP 191, a partir do qual o local de estudos está distante cerca de 1400m sentido Rio Claro.

O local foi ocupado pela Redistil Indústria Química Ltda e pela Indústria Química Sulfabrás S/A, entre os anos de 1981 e 1992. Dentre os produtos fabricados estão o dieloxalato, acetato de etila, 4-amino-N-2-tiozolilbenzeno-sulfonamida, acetopiruvato de metila, 5-metil-3carboxiamidoxazol (carboxiamido), e dentre os solventes utilizados durante 0 processo eram estão $0 \quad 1,2$ dicloroetano e o tolueno (CETESB, 1997)

Os solventes utilizados por ambas as indústrias eram reutilizados após passarem por colunas de destilação. As águas residuais deste processo passavam por um tacho de evaporação com objetivo de concentrar os efluentes. Em seguida, os efluentes gerados eram infiltrados em dois poços presentes no local. Este processo foi executado entre os anos de 1981 e 1988 (CETESB, 1997).

Em novembro de 1985 foram detectados odores em poços de abastecimento nos arredores da área de infiltração. Análises químicas realizadas em amostras coletadas em poços próximos a indústria indicaram contaminação da água subterrânea (Tabela 1). Posteriormente foram efetuadas análises químicas nos resíduos infiltrados com vistas á caracterização de sua composição química, cujo resultado permitiu correlação com as substâncias contaminantes presentes nas águas subterrâneas (CETESB, 1997).

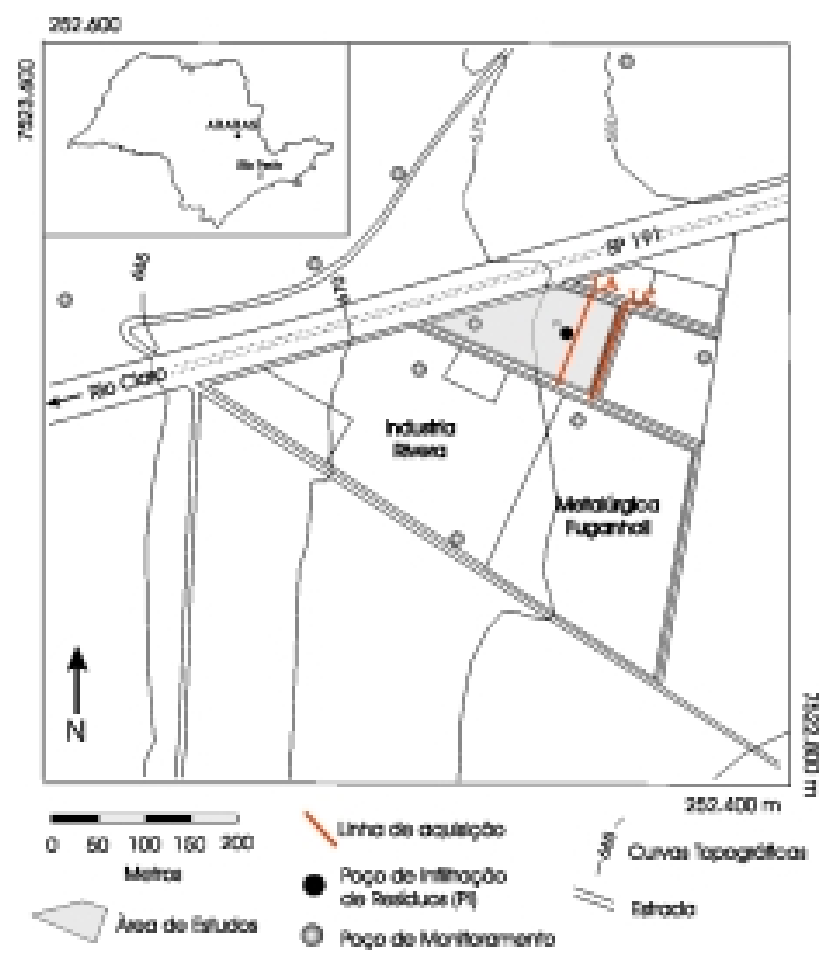

Figura 2 - Mapa de Localização

A partir de 1992, com o fechamento da indústria, a CETESB iniciou o monitoramento da atenuação natural dos contaminantes, a partir de diversos poços de monitoramento instalados na área e adjacências, em conjunto com a aplicação de técnicas geofísicas.

\begin{tabular}{|l|c|c|c|}
\hline Contaminante & $06 / 1990$ & $01 / 1992$ & $11 / 1999$ \\
\hline Benzeno $(\mu \mathrm{g} / \mathrm{L})$ & $29,5 \times 10^{3}$ & $6,0 \times 10^{3}$ & $1,19 \times 10^{4}$ \\
\hline Tolueno $(\mu \mathrm{g} / \mathrm{L})$ & $24,5 \times 10^{3}$ & $7,0 \times 10^{3}$ & $1,39 \times 10^{4}$ \\
\hline 1,2 Dicloroetano $(\mu \mathrm{g} / \mathrm{L})$ & $12 \times 10^{3}$ & 36,0 & 15,9 \\
\hline Sódio $(\mathrm{mg} / \mathrm{L})$ & 200,0 & $2,15 \times 10^{3}$ & $*$ \\
\hline Cloreto $(\mathrm{mg} / \mathrm{L})$ & $2,8 \times 10^{3}$ & $1,8 \times 10^{3}$ & $1,35 \times 10^{3}$ \\
\hline Sulfato $(\mathrm{mg} / \mathrm{L})$ & 32 & 31 & $<10$ \\
\hline
\end{tabular}

* - não analisado

Tabela 1 - Análises químicas em amostras coletadas no poço de monitoramento localizado na metalúrgica Fuganholi (CETESB, 1997)

\section{Fisiografia}

A área está localizada na porção nordeste da bacia sedimentar do Paraná, composta por rochas Paleozóicas (Grupo Itararé, Formações Tatuí, Irati e Corumbataí ), Mesozóicas ( Formações Pirambóia) e Cenozóicas ( 
Formação Rio Claro e depósitos atuais ) constituídas por sedimentos, derrames e intrusões básicas (CPRM, 1986). As litofácies presentes no local são siltitos argilosos pertencentes à formação Tatuí, representados por Latossolo vermelho escuro álico, com horizonte $A$ moderado de textura argilosa e horizonte B com textura média argilosa a muito argilosa (OLIVEIRA et. al., ,1981).

O aqüífero regional é representado pelo Sistema Tubarão, descontínuo em escala regional devido à presença de intrusões de diabásio. A circulação e o armazenamento de água ocorrem nos interstícios de arenitos, conglomerados e diamectitos. Nas proximidades da área de estudos, apresenta espessura superior à 400m (TONETTO, 2001). O lençol freático raso está situado em profundidades entre de 10,7 a 14,1 metros, com variações entre máximas entre 7,9 a 14,9 metros. O fluxo da água subterrânea nas proximidades dos pontos de infiltração de resíduos é para sudoeste. Dados de condutividade hidráulica proveniente de ensaios de infiltração em poços nas proximidades da área variam de $4,4 \times 10^{-7}$ a $7,0 \times 10^{-7}$ (CETESB, 1997).

\section{Resultados}

As sondagens geoelétricas foram integradas em linhas, a partir das quais foram produzidos mapas de resistividade aparente para o primeiro e segundo nível geoelétrico (Figuras 3,4,5,6).

O mapa de resistividade aparente para 5 metros de profundidade da linha LA apresenta uma anomalia de baixa resistividade entre as sondagens LA3 e LA4 (figura 3). Esta anomalia também está presente no mapa de resistividade aparente para 8 metros de profundidade, contudo, neste caso a porção central da anomalia fica restrita a área da sondagem LA3 (figura 4).

Esta anomalia de baixa resistividade está associada ao poço de injeção de resíduos, pois a projeção do poço na linha LA coincide com o intervalo anômalo.

A linha LC apresenta um grande intervalo com baixa resistividade, presente nos mapas de 5 e 10 metros de profundidade (figuras 5 e 6). No mapa de resistividade para 5 metros de profundidade, esta anomalia compreende o intervalo entre as sondagens LC1 e LC5, com tendência de diminuição da resistividade no sentido N190 (figura 5). No mapa de resistividade para 10 metros de profundidade, esta anomalia tende a se acentuar no sentido do poço de injeção de resíduos, e esta limitada entre as sondagens LC2 e LC 5 (figura 6).

\section{Conclusões}

A anomalia de baixa resistividade associada ao poço de injeção de resíduos representa a pluma de contaminação detectada em análises da água subterrânea.

A resposta física da pluma de contaminação, ou seja, sua caracterização como um corpo de baixa resistividade, pode estar associada aos tipos contaminantes presentes.
Os dados de análises químicas disponíveis no relatório da CETESB (CETESB, 1997), indicam que além dos compostos de Fase líquida não aquosa (NAPL), foram detectados valores excessivos em Sódio e Cloreto nas amostras de água subterrânea em poços na área e adjacentes a indústria (Tabela 1).

A presença destes íons em excessivas quantidades justificaria a anomalia de baixa resistividade. Entretanto, as sucessivas análises químicas demonstram que os teores de sódio e cloreto estão em declínio.

Desta maneira, a anomalia de baixa resistividade pode estar associada, em parte, a liberação de íons a partir da dissolução de minerais por ação de ácidos orgânicos. Estes ácidos são produzidos pela degradação de compostos derivados de petróleo, por ação de bactérias presentes naturalmente no ambiente.

\section{Agradecimentos}

O presente trabalho foi realizado com o apoio do Conselho Nacional de Desenvolvimento Científico Tecnológico - CNPq - Brasil.

Os autores agradecem ao técnico Francisco Manuel Garcia Barrera, do Departamento de Geologia Aplicada, UNESP - Rio Claro, pelo auxílio na execução dos trabalhos de campo.

\section{Referências Bibliográficas}

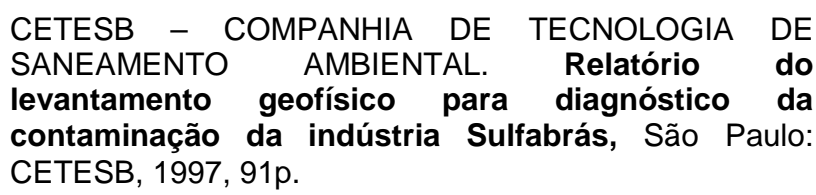

CPRM. Mapa Geológico do Município de Araras, escala 1.100.000. In: Projeto Borda Leste da Bacia do Paraná: Integração Geológica e Avaliação Econômica. Relatório Final, volume II, anexos, 1986.

OLIVEIRA, J.B., BARBIERI, J.L., ROTTA, C.L., TREMOICOLDI, W. A. Levantamento Pedológico semidetalhado do Estado de São Paulo: quadrícula Araras. Campinas: Convênio EMBRAPA/CPA/IA. 1981. escala 1:100.000.

TONETTO, E. M. Hidroquímica em aqüíferos de Rio Claro (SP) e adjacências. 2001. 108 p. Tese (Doutorado) Pós-Graduação em Geociências Instituto de

SHERIFF, E. R. Geophysical Methods, Prentice Hall, Chapter 9 - Electrical and Electromagnetic Methods, $\mathrm{p}$ 192-200, 1989.

TEMIX XL v4 Transient Electromagnetic Data Interpretation, User's Manual, Interpex limited, 1996. 

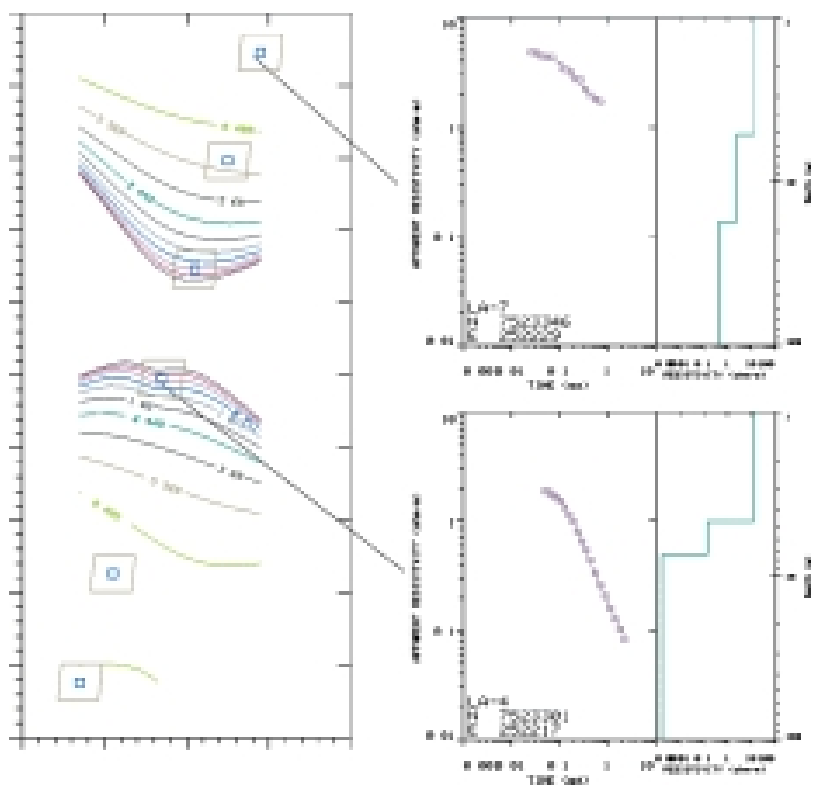

Figura 3 - Mapa de resistividade da linha LA para a profundidade de 5 metros, com curvas e modelos de resistividade.
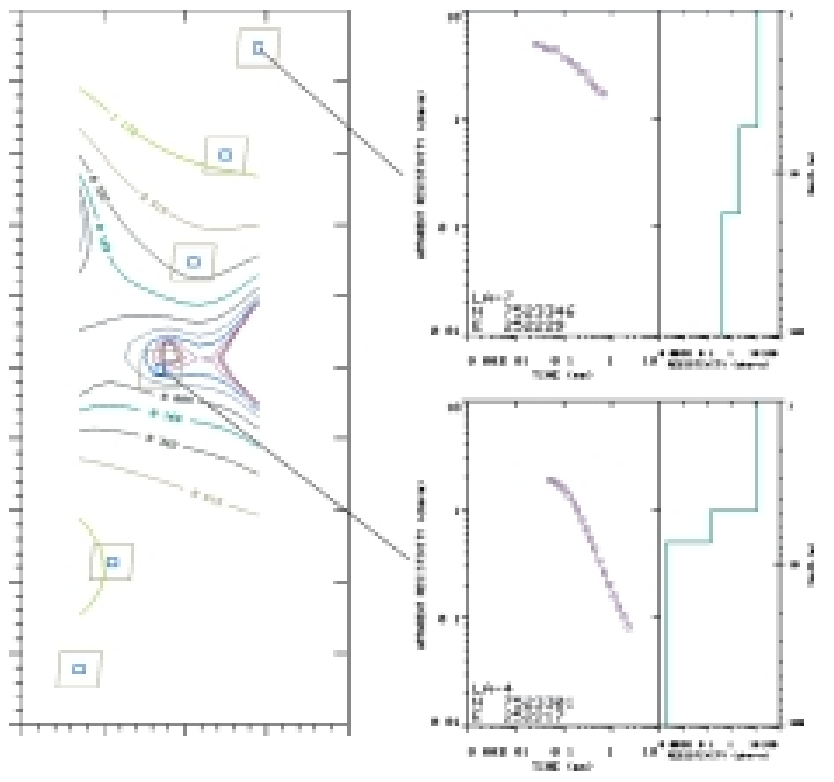

Figura 4 - Mapa de resistividade da linha LA para a profundidade de 8 metros, com curvas e modelos de resistividade.

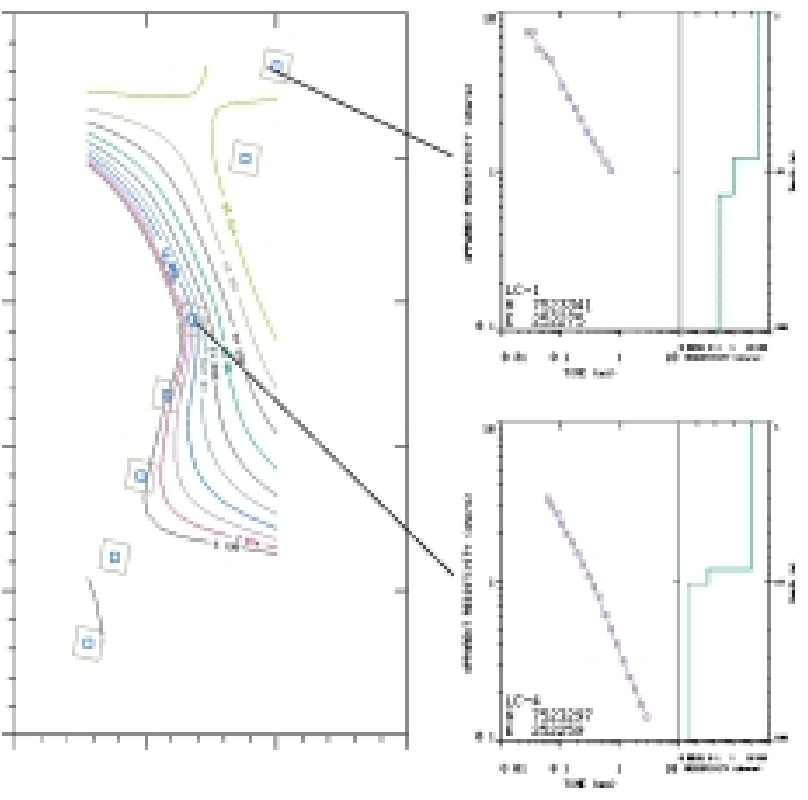

Figura 5 - Mapa de resistividade da linha LC para a profundidade de 5 metros, com curvas e modelos de resistividade.

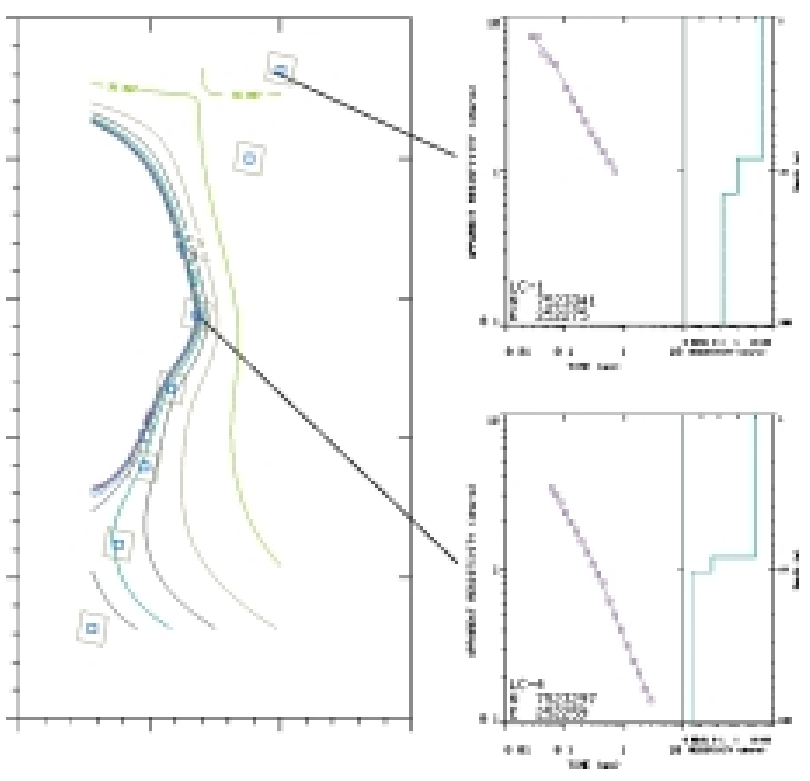

Figura 6 - Mapa de resistividade da linha LC para a profundidade de 10 metros, com curvas e modelos de resistividade. 